\title{
Um Jogo Sério para Suportar o Aprendizado do Modelo Atômico de Bohr
}

\author{
Adilson Vahldick, Willeson Thomas da Silva \\ Universidade do Estado de Santa Catarina (Udesc Alto Vale) \\ adilson.vahdick@udesc.br, will.thomassilva@gmail.com
}

\begin{abstract}
Resumo. Um dos grandes problemas no ensino de física e química nas escolas é a carência dos laboratórios para que os alunos pratiquem e concretizem aquilo que visitaram de forma abstrata nas aulas teóricas. $\mathrm{O}$ uso de jogos na educação oferece oportunidades significativas de aprendizagem com a esperança de aumentar o interesse dos jovens nos conteúdos educacionais. O jogo, descrito neste artigo, permite que o aluno aprenda conceitos básicos do Modelo Atômico de Bohr. É um jogo do gênero ação, em que o aluno pilota uma nave que dispara projéteis. Entre cada uma das seis fases, ocorre um diálogo com o Dr. Niels Bohr, que explica o modelo e encerra com uma tarefa. Uma turma $(\mathrm{n}=28)$ do primeiro ano de ensino médio de uma escola pública experimentou o jogo. Os testes estatísticos apresentaram uma melhora significativa no desempenho após a experiência com o jogo. Apesar dos alunos terem achado alguma dificuldade em vencer no jogo, eles concordaram que se sentiram satisfeitos em divertir-se aprendendo com o jogo.
\end{abstract}

Palavras-chaves. Química. Física. Jogos sérios. Modelo atômico de Bohr.

\section{A Serious Game to Support the Learning of Bohr's Atomic Model}

Abstract. One of the major problems in the teaching of physics and chemistry in schools is the lack of laboratories for students to practice and materialize what they have visited in an abstract way in theoretical classes. The use of games in education offers significant learning opportunities with the hope of increasing young people's interest in educational content. The game, described in this article, allows the student to learn basic concepts of Bohr's Atomic Model. It is a game of the action genre, in which the student pilots a ship that fires projectiles. Between each of the six phases, there is a dialogue with Dr. Niels Bohr, who explains the model and ends with a task. A class $(n=28)$ of the first year of high school in a public school tried the game. Statistical tests showed a significant improvement in performance after the experience with the game. Although the students found it difficult to win in the game, they agreed that they were happy to have fun learning with the game.

Keywords. Chemistry. Physics. Serious games. Bohr's atomic model.

\section{Introdução}

O modelo atômico de Bohr, apesar de não ser o modelo mais atual de átomo aceito pela comunidade científica, ainda é utilizado para explicar diversos fenômenos observados em nosso cotidiano. Peduzzi e Basso (2005) afirmam que a natureza e a complexidade do conteúdo de química e física moderna, aliada ao delineamento e implantação de estratégias para a sua abordagem didática, seja pelo autor de livro-texto, ou pelo professor, abre à pesquisa um campo de estudos bastante promissor. Em relação ao ensino desse modelo em sala de aula, percebe-se a pouca ênfase dada aos fatos do cotidiano através de atividades diferenciadas, resultando na falta de interesse por parte dos estudantes (Silva, 2013). Romanelli (1996) afirma que a aprendizagem do conceito de átomo demanda o envolvimento de noções abstratas, concepções de modelos, palavras e símbolos. Isso evidencia a necessidade na utilização de diferentes estratégias de ensino. 
O ensino das ciências físicas e naturais no país está fortemente influenciado pela ausência da prática experimental, dependência excessiva do livro didático, método expositivo, reduzido número de aulas, currículo desatualizado e descontextualizado e profissionalização insuficiente do professor (Pedrisa, 2008). Nessa perspectiva, tem-se ainda a ausência de laboratórios para o ensino de ciências físicas e naturais, dificultando ainda mais o aprendizado do aluno no contexto científico. Segundo Binsfeld e Auth (2011), a ausência de laboratórios para realização de experimentos traduz-se em um obstáculo pedagógico à consecução do ensino e da aprendizagem da química nos diferentes níveis e modalidades da escolarização, com impacto negativo sobre o entendimento e o interesse por essa ciência.

Assim, o uso de tecnologias pode aumentar o interesse dos alunos em estudar devido às inovações apresentadas pelos artifícios tecnológicos. No cenário educacional, torna-se de grande ajuda para o processo de ensino-aprendizagem a implantação de métodos que priorizem não apenas a parte conceitual dos assuntos abordados em sala de aula como também o incentivo dos alunos em atividades práticas. A utilização de tecnologias no atual cenário educacional visa potencializar o aprendizado dos alunos com o intuito de despertar o interesse destes em disciplinas ligadas às ciências exatas.

O jogo educacional oferece um mecanismo alternativo de aprendizagem que devem ser usados adequadamente pelos professores como um poderoso motivador para $\mathrm{o}$ início do processo de aprendizagem, estimulando as relações cognitivas, além de prover uma reação ativa, crítica e criativa dos educandos, socializando o conhecimento (Tarouco et al., 2004). Os jogos sérios são ambientes simulados que possibilitam testar, acertar e errar diversas vezes, respeitando o tempo cognitivo do educando, auxiliando para o seu aprendizado e aplicação prática (Herpich et al., 2013).

Diante da perspectiva de fornecer um recurso lúdico que auxilie os professores na motivação dos alunos sobre o aprendizado de química, esta pesquisa apresenta um jogo sério desenvolvido em que o jogador controla uma nave que precisa proteger o planeta da eminente invasão alienígena. Para combater o inimigo, é preciso recarregar a nave com munição e isso acontece no laboratório de Niels Bohr. Nesse momento o cientista dialoga com o aluno lhe explicando alguns conceitos de sua descoberta modelo atômico dele. Ao final, o aluno resolve um problema utilizando como ferramenta a tabela periódica. O jogo foi validado com 28 alunos do primeiro ano do Ensino Médio de uma Escola Estadual. Foram realizados pré e pós testes, e avaliado o grau de satisfação deles com o jogo.

Em relação às pesquisas sobre produção de jogos para o aprendizado de química, observou-se que existem várias iniciativas de jogos não-digitais (SARMENTO; OLIVEIRA, 2018; MEDEIROS et al., 2020). Em relação a trabalhos correlatos, ou seja, jogos digitais, concluiu-se uma preocupação em se envolver sempre com tabelas periódicas (Duarte et al., 2017; Faria et al., 2018). Dessa forma, o jogo descrito neste artigo também usará a Tabela Periódica como ferramenta para relacionar com o Modelo Atômico de Bohr.

Este artigo está organizado da seguinte forma: a Seção 2 apresenta um resumo do modelo atômico de Bohr considerado no desenvolvimento do jogo; a Seção 3 relata a metodologia utilizada nessa pesquisa para o seu desenvolvimento e a sua validação; a Seção 4 descreve o jogo desenvolvido; a Seção 5 apresenta a validação do jogo. Por fim, a Seção 6 apresenta a conclusão dessa pesquisa. 


\section{Modelo Atômico de Bohr}

A física moderna teve avanços significativos com Niels Bohr em sua publicação considerada um dos trabalhos mais importantes do século XX, no qual ele apresentou pela primeira vez um modelo do átomo construído a partir de fatos experimentais e da hipótese de quantização de energia de Max Planck (Parente et al., 2013). Bohr postulou que (Peruzzo \& Canto, 2015):

1. Os elétrons, nos átomos, movimentam-se ao redor do núcleo em trajetórias circulares, chamadas de camadas ou níveis;

2. Cada um desses níveis tem um valor determinado de energia;

3. Não é permitido a um elétron permanecer entre dois desses níveis;

4. Um elétron pode passar de um nível para outro de maior energia, desde que absorva energia externa (ultravioleta, luz visível etc.). Quando isso acontece, diz-se que o elétron foi excitado e que ocorreu uma transição eletrônica (Figura 1a);

5. O retorno do elétron ao nível inicial é acompanhado pela liberação de energia na forma de ondas eletromagnéticas, por exemplo, como luz visível ou ultravioleta (Figura 1b).
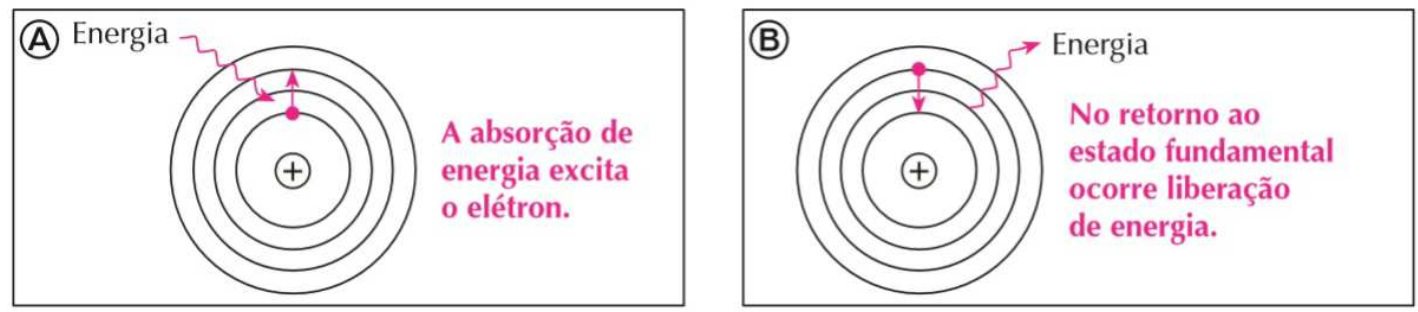

Figura 1 - Transição eletrônica do elétron.

Fonte: Peruzzo e Canto (2015).

O elétron do átomo de hidrogênio no estado fundamental pode absorver várias quantidades discretas de energia e, assim se elevar a um nível de energia mais alto (Feltre, 2005). Quando a luz visível é absorvida em compostos químicos, seus elétrons são excitados do estado fundamental para o estado excitado. A energia absorvida geralmente é emitida na forma de radiação eletromagnética na região do visível, que varia do vermelho ao violeta (Silva, 2013). A Figura 2 apresenta o teste de chama, que demonstra o princípio da transição eletrônica de Bohr. O calor excita os elétrons fazendo com que passem para níveis de maior energia. Ao voltarem aos níveis iniciais, liberam energia na forma de luz, cuja cor é característica dos átomos de cada elemento (Peruzzo \& Canto, 2015).
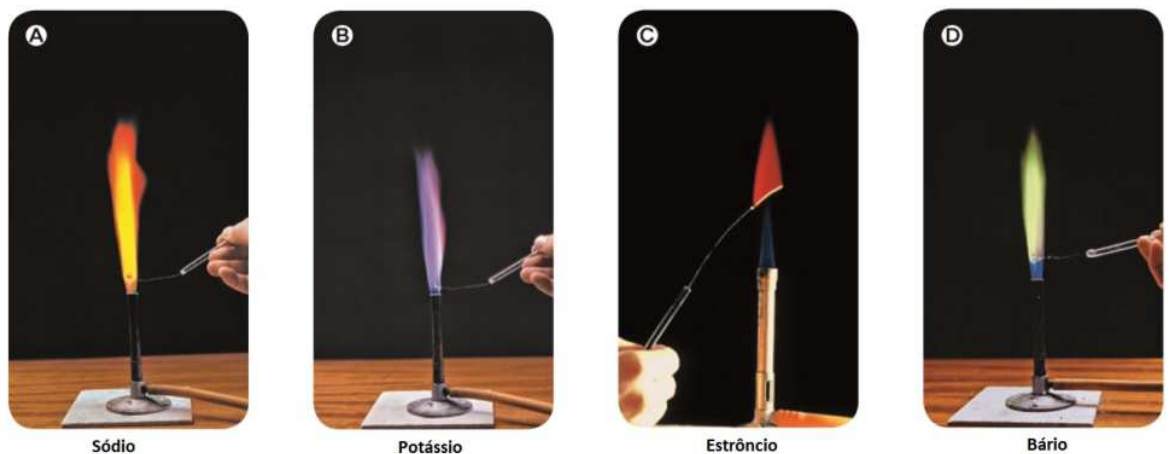

Figura 2 - Interpretação da cor no teste de chama. Fonte: Adaptado de Peruzzo e Canto (2015).

V. $18 \mathrm{~N}^{\mathrm{o}} 1$, julho, 2020

DOI: 


\section{Metodologia da Pesquisa}

Para o desenvolvimento dessa pesquisa contou-se com o apoio de um professor de química do Ensino Médio, que recomendou a lacuna a ser preenchida usando o jogo. $\mathrm{O}$ professor forneceu e indicou material bibliográfico sobre o modelo atômico de Bohr a ser abordado. Também já estabeleceu a turma, o período e o protocolo de validação do jogo.

Em seguida, foram coletadas informações sobre o desenvolvimento de jogos sérios de química em relação às suas particularidades pedagógicas e estudados alguns jogos similares. Depois, houve um estudo técnico sobre o desenvolvimento de jogos quanto às ferramentas e métodos. Com base nessas informações, foi decidido desenvolver um jogo de ação e definidos o enredo, os personagens, os desafios do jogo e a estética.

O jogo foi desenvolvido com Unreal Engine ${ }^{1}$ usando scripts em Blueprints ${ }^{2}$. O jogo desenvolvido passou por testes de usabilidade e garantia da qualidade pela equipe do Laboratório de Pesquisa e Desenvolvimento de Jogos Sérios e para Entretenimento (GameLab).

O protocolo de validação do jogo foi determinado da seguinte forma (Figura 3): o professor lecionou uma aula sobre o Modelo Atômico de Bohr para uma turma de 28 alunos do primeiro ano do Ensino Médio. Em outro dia na mesma semana aconteceu a validação do jogo. Em momentos distintos foram aplicados testes (pré e pós) com 8 questões de múltipla escolha, que variavam sua ordem, tanto nas questões quanto nas respostas. O pré-teste teve o objetivo de medir o prévio grau de conhecimento dos alunos em relação aos objetivos educacionais já relacionados. Os alunos experimentaram o jogo durante uma hora sentados em duplas em cada computador, podendo assim alternaremse com achavam melhor. Após o jogo, responderam o pós-teste que tinha a intenção de verificar o quanto o jogo contribuiu no conhecimento adquirido pelos alunos. Após os testes, responderam um inquérito com 26 itens baseado no MEEGA+ Kids (Wangenheim et al., 2018) visando avaliar a experiência do jogo. Esse inquérito também tinha três questões abertas: "O que você aprendeu jogando esse jogo?", "O que você gostou no jogo?" e "O que você achou ruim?".

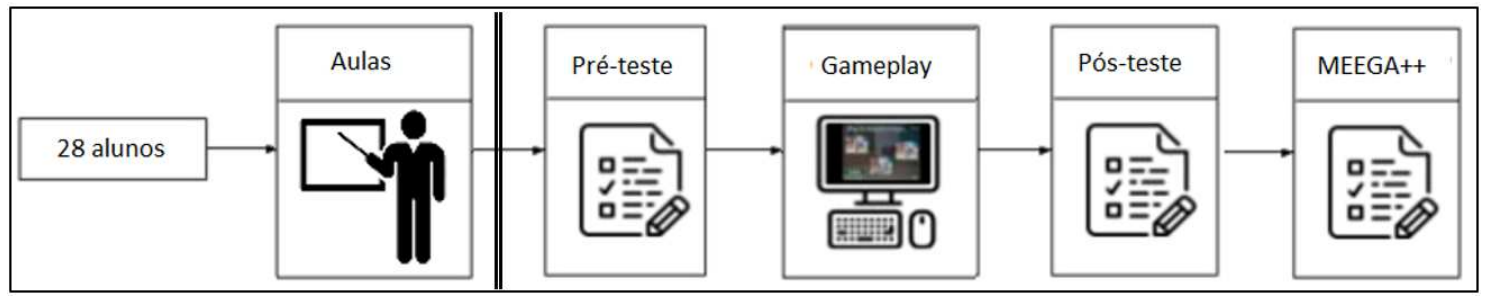

Figura 3 - Protocolo de Validação

\section{Jogo Desenvolvido: O Mundo Quântico de Bohr}

O jogo está disponível em Windows 64 bits para download em https://www.udesc.br/ceavi/gamelab/tccs/willesonthomasdasilva. O gênero do jogo é ação em terceira pessoa. As mecânicas são pilotar a nave nos três eixos e disparar projéteis em três cores diferentes. Para destruir um inimigo, o projetil deve ser da mesma cor do inimigo.

Como objetivos pedagógicos foram determinados: (a) entender as mudanças de camadas pelos elétrons; (b) conhecer que elementos diferentes emitem cores distintas

\footnotetext{
${ }^{1} \mathrm{http} / / / \mathrm{www}$.unrealengine.com

${ }^{2}$ https://docs.unrealengine.com/en-US/Engine/Blueprints/index.html V. $18 \mathrm{~N}^{\circ} 1$, julho, 2020 DOI:
} 
quando ocorrem o salto quântico; (c) compreender que os elétrons não podem ocupar qualquer nível de energia; e (d) correlacionar as características dos elementos quanto aos seus níveis de energia e como estes podem ser identificados na tabela periódica.

O jogo possui seis fases. Antes de cada fase, o aluno é levado ao laboratório do Dr. Niels Bohr. O formato do laboratório está exemplificado na Figura 4. Observa-se na parte inferior uma caixa com o rosto do cientista com seu diálogo, onde ele explica, às vezes com ilustrações, sobre o funcionamento do modelo atômico. Ao final, ele sempre lança um desafio. A área da Tabela Periódica tem alguns elementos ressaltados que representam as opções que ele pode clicar para responder à pergunta. $\mathrm{O}$ aluno somente avança para o jogo quando acertar a questão. Então ele pode realizar várias tentativas. Porém, cada tentativa desconta uma quantidade de pontos.

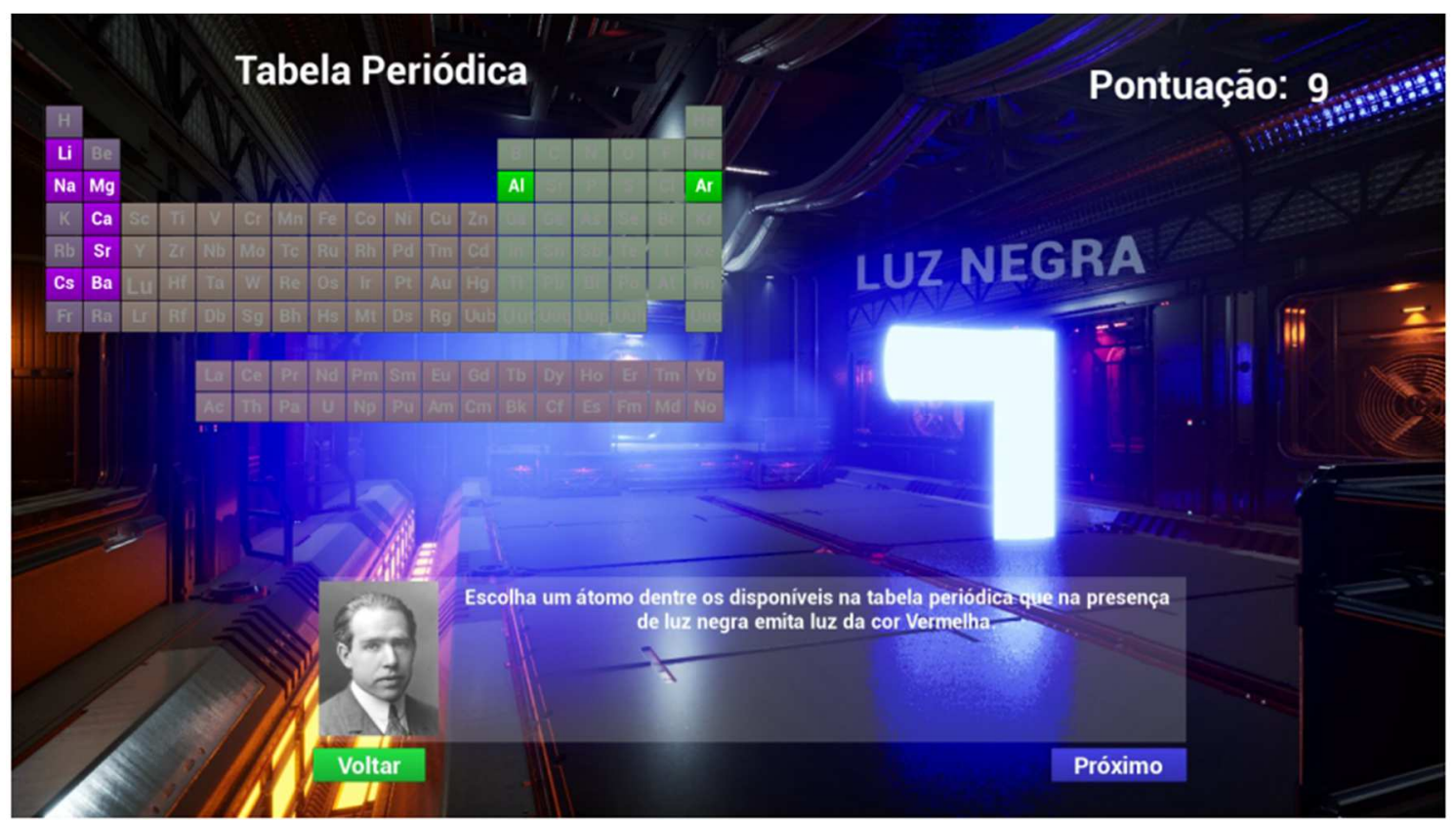

Figura 4 - Laboratório de Niels Bohr

Pilotar a nave e destruir os inimigos é de característica lúdica no jogo, servindo de motivação para que eles vençam os desafios do Dr. Bohr. As Figuras 5 e 6 ilustram duas fases do jogo. A Figura 5 corresponde à primeira fase que tem como objetivo treinar o aluno no jogo. As peças vão aleatoriamente mudando de posição, e ele tem que disparar o projetil da mesma cor da peça. A Figura 6 corresponde à terceira fase onde acontece uma perseguição de naves. As inimigas também disparam no jogador. Pode-se observar no canto superior esquerdo uma barra de energia representando quantos disparos a nave do jogador ainda suporta ser atacada.

Com esses dois exemplos, pode-se observar que a equipe primou para que cada fase oferecesse de fato um desafio diferente, reforçando o estímulo da curiosidade. Por exemplo, uma das fases tem contagem regressiva para a explosão de uma bomba que precisa ser desarmada, e outra fase, o jogador precisa destruir uma nave de grande porte atingindo seus pontos fracos.

\section{Resultados da Validação}

O estudo teve como objetivo a avaliação do conhecimento adquirido entre os dois momentos da validação, conforme a hipótese estatística abaixo. 


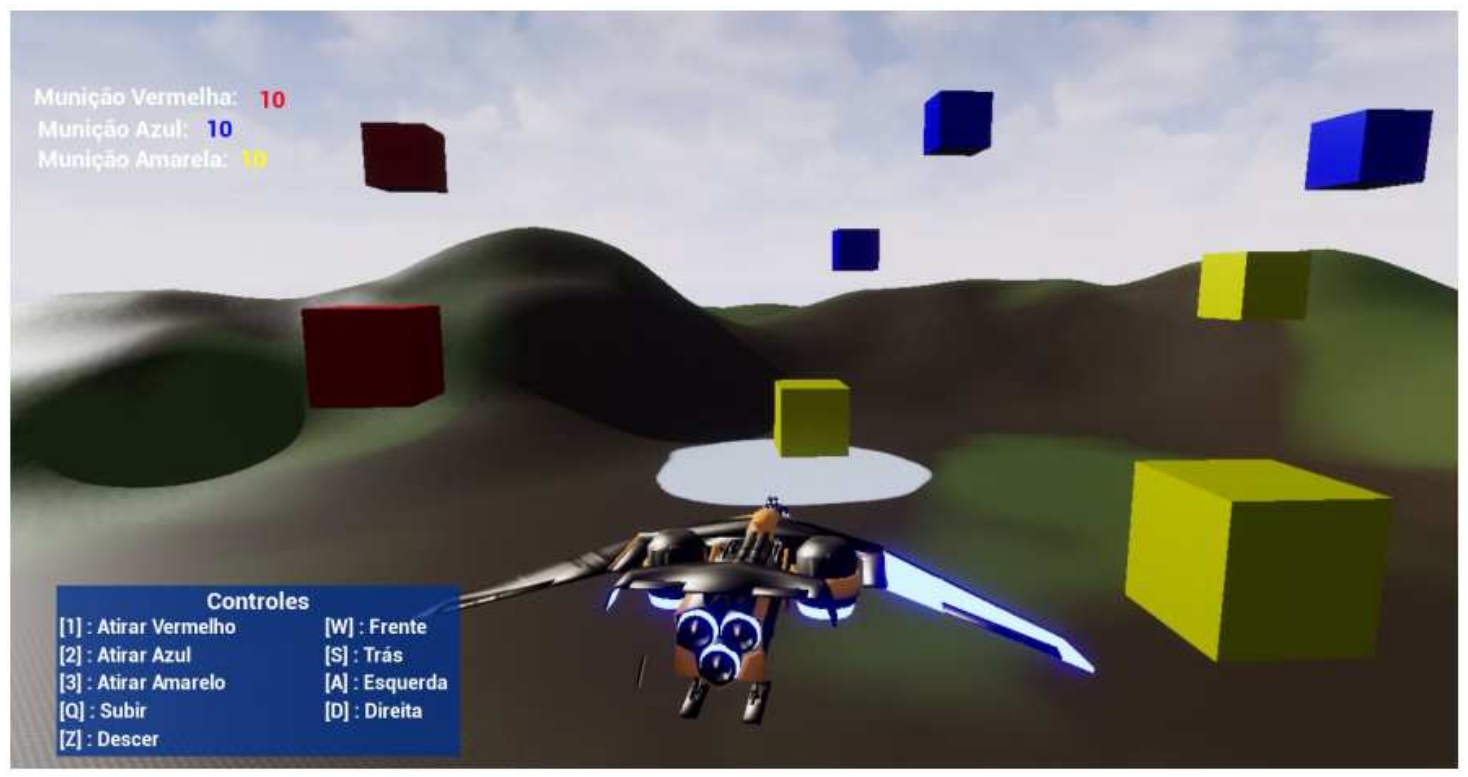

Figura 5 - Primeira fase do jogo

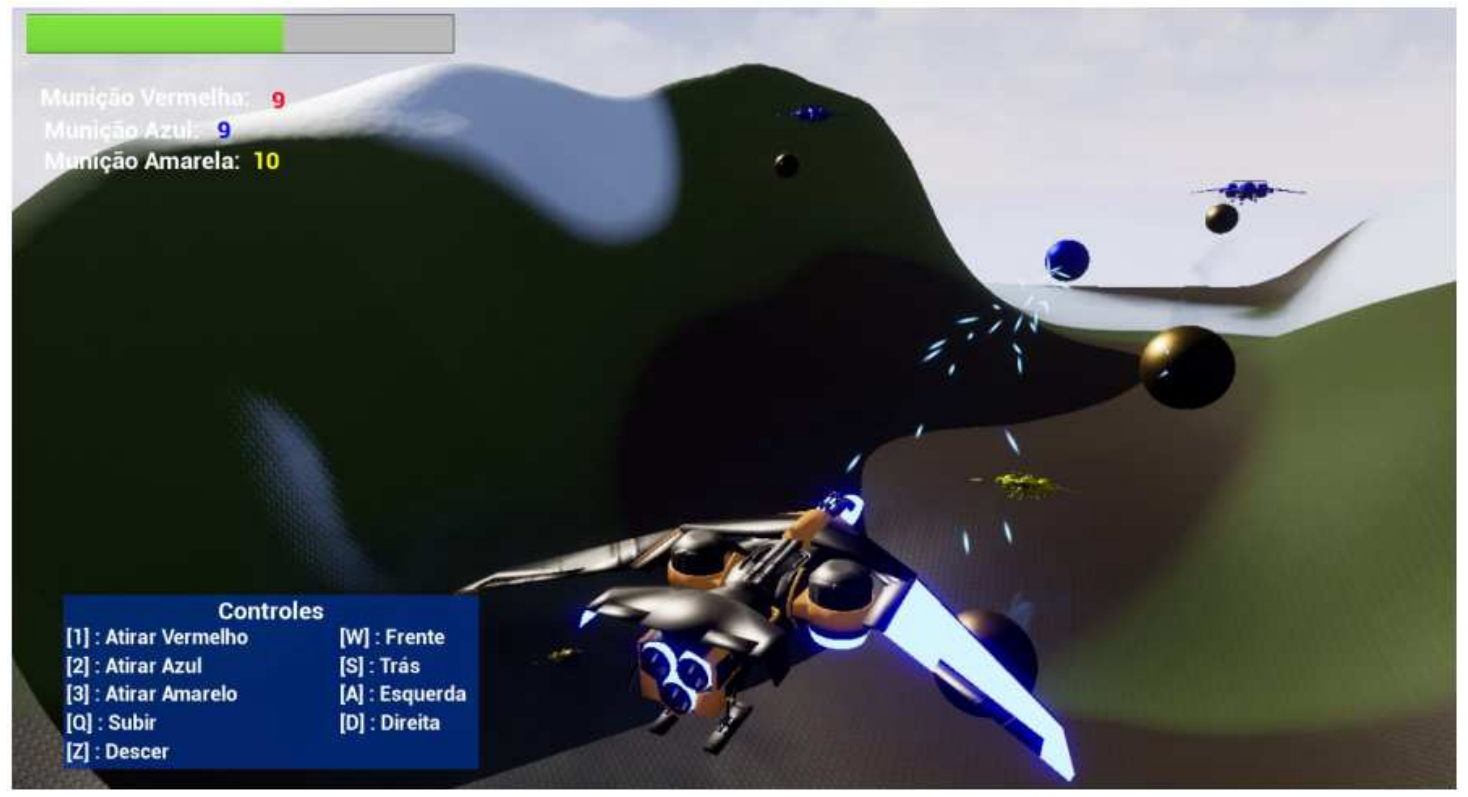

Figura 6 - Terceira fase do jogo

$H_{0}: \mu_{\text {pré }}=\mu_{\text {pós-final }}-$ Não existe diferença significativa nas médias entre os testes antes e depois do jogo.

A Tabela 1 apresenta as estatísticas descritivas dos testes. É importante lembrar que os testes tinham oito questões. Os valores da tabela foram todos normalizados considerando uma nota 10 quando todas as questões estavam corretas. Participaram da validação 28 alunos do primeiro ano do ensino médio. É possível notar que as médias de todos os testes foram abaixo de 5,0. Adicionalmente a Figura 7 apresenta as notas obtidas de cada um dos 28 alunos em cada teste. Aproximadamente $71 \%$ dos alunos tiveram desempenho melhor entre o Pré-Teste e o Pós-Teste. 
Tabela 1 - Estatística descritiva dos testes de conhecimento

\begin{tabular}{l|c|c|c|c|c|c}
\hline & $\begin{array}{c}\text { Total de } \\
\text { Pontos } \\
\text { Possíveis }\end{array}$ & $\begin{array}{c}\text { Total de } \\
\text { Pontos } \\
\text { Conquis- } \\
\text { tados }\end{array}$ & Média & Mediana & $\begin{array}{c}\text { Desvio } \\
\text { padrão }\end{array}$ & Variância \\
\hline Pré-Teste & 280 & 90 & 3,21 & 3,75 & 1,78 & 3,17 \\
\hline Pós-Teste & 280 & 117,5 & 4,19 & 4,38 & 1,99 & 3,96 \\
\hline
\end{tabular}

\section{Comparativo do desempenho entre}

pré e pós-teste

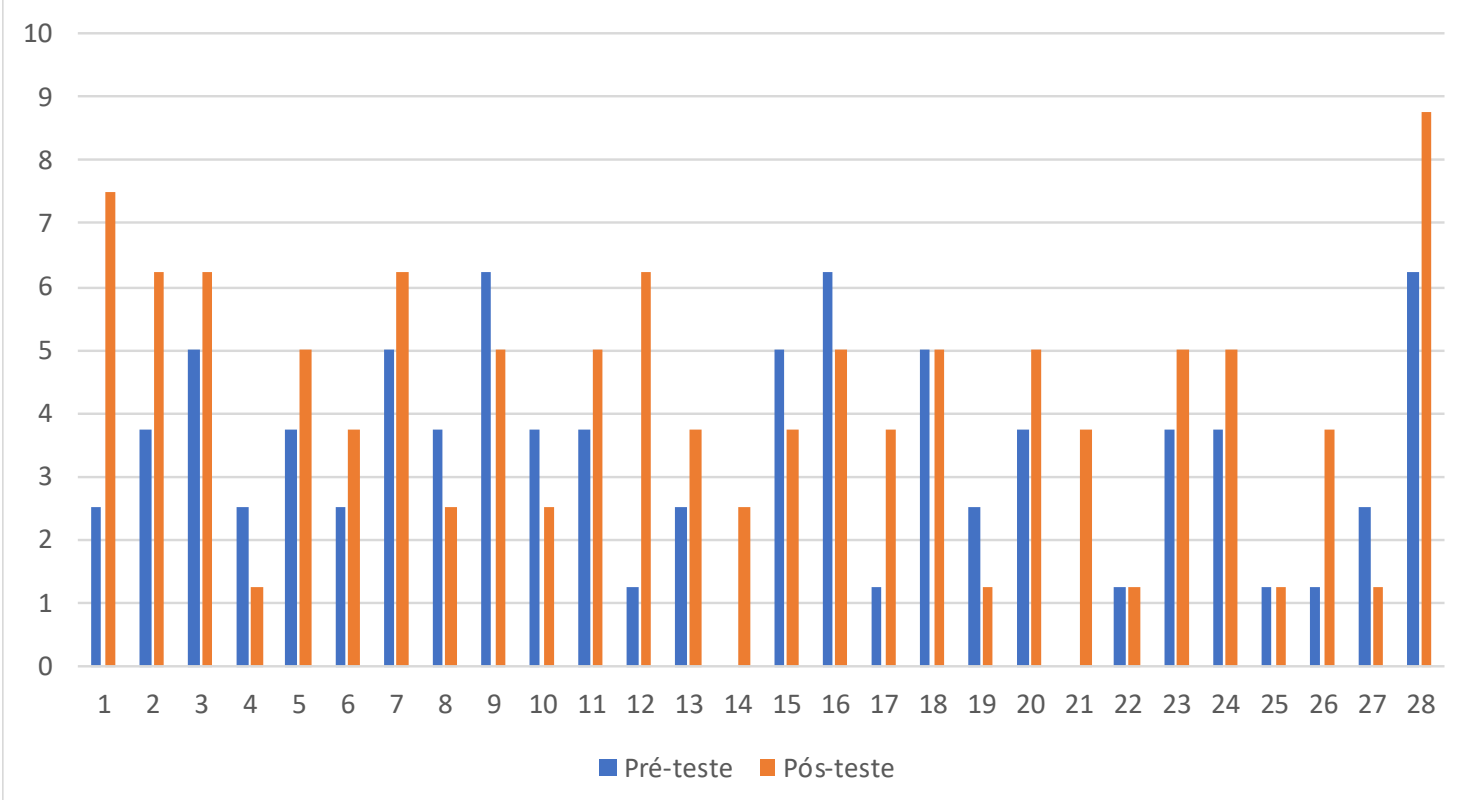

Figura 7 - Desempenho individual nos testes

Porém, para conferir se a diferença é estatisticamente significativa, deve-se avaliar a hipótese estatística, e para isso foi executado o teste $t$ pareado. $\mathrm{O}$ resultado de p-valor= 0,009956, rejeita a hipótese nula com $99 \%$ de confiança de que o desempenho foi o mesmo entre os dois testes. Como a média do pós-teste foi maior do que o pré-teste, podese concluir que o desempenho foi melhor após o jogo.

Para finalizar os testes, foi aplicado o instrumento MEEGA+ Kids para avaliar a experiência de jogo. A escala desse instrumento objetiva classificar jogos educativos em relação ao seu nível de qualidade, baseado nas percepções do estudantes, permitindo identificar quais requisitos correspondem ao mais baixo ou alto nível de qualidade (Wangenheim et al., 2018). Ele é composto de 26 questões agrupados em onze dimensões (1-estética, 2-aprendibilidade, 3-operabilidade, 4-acessibilidade, 5-desafio, 6-satisfação, 7-interação social, 8-diversão, 9-atenção concentrada, 10-relevância e 11-aprendizagem percebida) na escala likert com cinco níveis de concordância de discordo totalmente a concordo totalmente.

A escala likert é de natureza qualitativa ordinal, pois existe uma ordem natural entre os itens da escala (p.e., entre discordo totalmente e concordo totalmente). Para realizarem-se operações algébricas normalmente acaba-se transformando a escala em V. $18 \mathrm{~N}^{\mathrm{o}} 1$, julho, 2020 RENOTE DOI: 
quantitativa discreta (neste caso, pontuando-a de 1 a 5). Quando isso é feito, admite-se incorretamente que existe uma relação linear entre os níveis de concordância. Neste contexto, Tastle, Russell e Wiermann (2008) propõem um novo índice para complementar a interpretação dos resultados obtidos a partir dos questionários. $\mathrm{O}$ nome deste índice é Consenso $(C n s(x))$, e é calculado pela equação abaixo, onde $E(x)$ é a esperança matemática, ou seja, "o que se espera com mais e mais replicações dos questionários".

$$
\operatorname{Cns}(x)=1+\sum_{i=1}^{k} P\left(x_{i}\right) \log _{2}\left(1-\frac{\left|x_{i}-E(x)\right|}{X_{\max }-X_{\min }}\right)
$$

O Cns $(x)$ deve ser interpretado como um percentual de concordância interna da distribuição no que diz respeito a $E(x)$. Como $0 \leq \operatorname{Cns}(x) \leq 1$, entende-se que, quanto mais próximo de 1, mais os respondentes "concordam" com o valor esperado para a questão. Um conceito complementar ao Consenso é o de Divergência $(D v g(x))$ e esta é dada simplesmente por $1-\operatorname{Cns}(x)$. A Tabela 2 apresenta computadas a esperança matemática, índice de consenso e divergência das respostas dos 28 alunos, dentro dos cinco níveis de concordância, onde 1-discordo totalmente e 5-concordo totalmente.

Tabela 2 - Resultados da avaliação com o MEEGA+ Kids

\begin{tabular}{cccccccccccc}
\hline & $\mathbf{1}$ & $\mathbf{2}$ & $\mathbf{3}$ & $\mathbf{4}$ & $\mathbf{5}$ & $\mathbf{6}$ & $\mathbf{7}$ & $\mathbf{8}$ & $\mathbf{9}$ & $\mathbf{1 0}$ & $\mathbf{1 1}$ \\
\hline $\mathbf{E}(\mathbf{x})$ & 3,84 & 4,46 & 4,05 & 3,95 & 3,62 & 4,03 & 4,12 & 4,27 & 3,80 & 4,09 & 3,95 \\
Consenso & $\mathbf{0 , 6 6}$ & $\mathbf{0 , 8 1}$ & $\mathbf{0 , 6 9}$ & $\mathbf{0 , 6 7}$ & $\mathbf{0 , 6 0}$ & $\mathbf{0 , 7 1}$ & $\mathbf{0 , 6 5}$ & $\mathbf{0 , 7 0}$ & $\mathbf{0 , 6 0}$ & $\mathbf{0 , 6 5}$ & $\mathbf{0 , 6 2}$ \\
Divergência & 0,34 & 0,19 & 0,31 & 0,33 & 0,40 & 0,29 & 0,35 & 0,30 & 0,40 & 0,35 & 0,38 \\
\hline
\end{tabular}

Analisando os valores de cada uma das dimensões, pode-se afirmar que houve convergência (a maioria qualificada (3/5) dos alunos, ou seja, acima de 60\%) nas esperanças tendendo a concordo (estavam todas acima de 3,5), em todas as dimensões. A dimensão mais baixa foi desafio (5) com 3,62, que ao mesmo tempo foi com o menor consenso $(0,60)$. Avaliando individualmente as três questões que compõe essa dimensão, encontramos com $E(x)=3,14$, com $\operatorname{Cns}(x)=0,58$ a questão "Este jogo é desafiador suficiente para mim", juntamente com as questões abertas (Figura 8), encontra-se que os alunos acharam o jogo difícil. Porém, as dimensões de satisfação (6) e diversão (8) alcançaram esperanças acima de 4,0 com concordância da grande maioria, indicando que apesar da dificuldade, os alunos se divertiram com o jogo. A dimensão 11 representa a aprendizagem percebida pelo aluno, ou seja, sua crença e sentimentos em relação a aprendizagem ocorrida (Caspi \& Blau, 2008) e reflete o senso do estudante que algum novo conhecimento foi adquirido e alguma nova compreensão foi alcançada, mesmo que esse conhecimento e compreensão subjetivos estiverem em contraste com o desempenho acadêmico (Caspi \& Blau, 2011). Como essa aprendizagem representa o grau de confiança que o aluno tem em relação ao seu domínio de um dado conhecimento, os alunos, mesmo não conhecendo os resultados finais dos seus testes, encerraram o experimento com a sensação de que adquiriram o conhecimento esperado.

Em relação às questões abertas, 20 alunos responderam a primeira "O que você aprendeu jogando esse jogo?" com "Modelo atômico de Bohr e os seus níveis de energia". Outros seis responderam de terem trabalhado em equipe. A Figura 8 apresenta categorizada as respostas das duas outras questões abertas "O que você gostou no jogo?" e "O que você achou ruim?". 

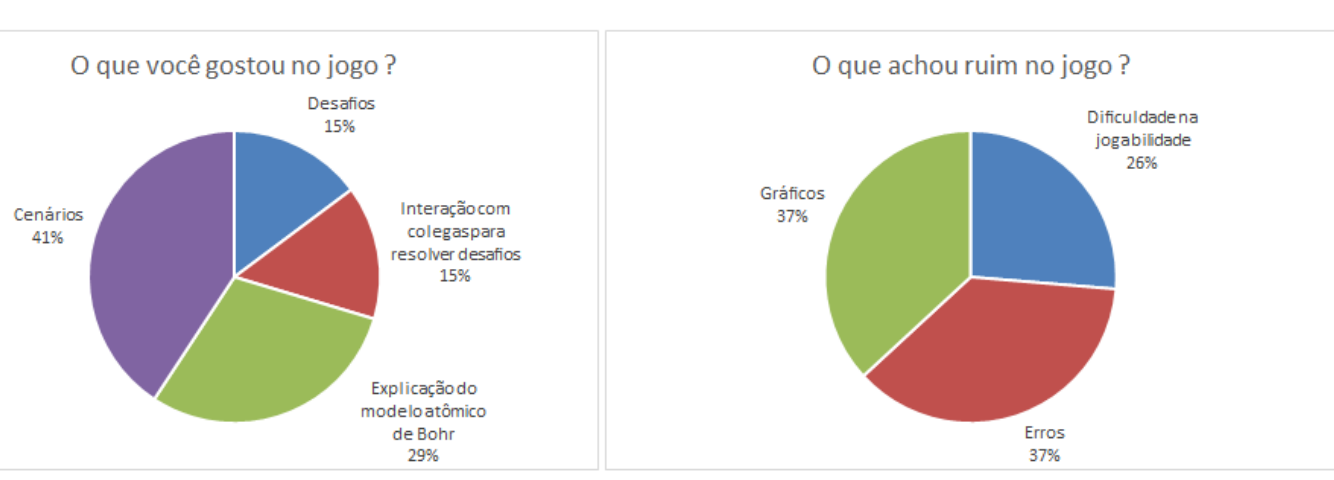

Figura 8 - Respostas categorizadas (a) O que você gostou no jogo ? (b) O que achou ruim no jogo?

É interessante observar que tanto na questão do que aprendeu com o jogo, quanto o que gostaram no jogo, houveram respostas sobre a satisfação em ter jogado em duplas. Apesar de estar fora do escopo desse trabalho, isso demonstra como os alunos acham importante e motivador trabalhar ou estudar com outro colega. Apesar da dimensão de desafios ser a pior avaliada, alguns alunos gostaram dos desafios oferecidos no jogo. Além disso, apesar de que $37 \%$ deles não gostaram dos gráficos, $41 \%$ gostaram dos cenários, ou seja, gostaram da narrativa em que estavam inseridos. Por último, 29\% dos alunos gostaram do jogo por ele ser educativo.

\section{Conclusões}

O ensino de físico-química moderna destaca-se como um desafio para os alunos, devido à sua modelagem matemática como também ao nível de abstração necessário para sua completa compreensão. Este estudo teve como objetivo desenvolver uma alternativa educativa significativa propondo um jogo sério como uma atividade para o aprendizado do Modelo Atômico de Bohr.

Ambos os testes apresentaram médias muito baixas, no pré-teste com 3,21 e no pós-teste com 4,19. Porém, ao comparar ambas as médias, pôde-se concluir com significância estatística que os alunos evoluíram no desempenho. Mesmo assim, o baixo rendimento dos alunos foi preocupante. É fora do escopo desse trabalho, mas precisa-se verificar se o problema é de interpretação de textos e/ou domínios básicos de abstração.

Conforme a opinião dos alunos, o jogo demonstrou sua eficiência no aprendizado e na diversão. A dimensão pior avaliada foi a de desafio com os alunos achando que o jogo não estava tão fácil de ganhar. Como trabalho futuro deve-se avaliar melhor onde e como os alunos estão sentindo a dificuldade no jogo. Além disso, inserir novas tarefas e atividades fornecidas pelo Dr. Bohr.

\section{Referências}

Binsfeld, S. C., \& Auth, M. A. (2011). A Experimentação no Ensino de Ciências da Educação Básica : constatações e desafios. In VIII Encontro Nacional de Pesquisa em Educação em Ciências (VIII ENPEC) e I Congreso Iberoamericano de Investigación de las Ciencias (I CIEC). Resumos. Campinas/SP (pp. 1-10).

Caspi, A., \& Blau, I. (2008). Social presence in online discussion groups: Testing three conceptions and their relations to perceived learning. Social Psychology of Education, 11(3), 323-346.

Caspi, A., \& Blau, I. (2011). Collaboration and psychological ownership: How does the tension between the two influence perceived learning? Social Psychology of 
Education, 14(2), 283-298.

Duarte, D. W. A., Silva, I. W. P. da, \& Duarte, A. K. F. (2017). Q-Memória: Um jogo da memória digital para o estudo de Química no ensino médio. In II Congresso sobre Tecnologias na Educação (Vol. 1877, pp. 655-661).

Faria, P. A. R., Silva, L. H. F. P., \& Sousa, P. M. de. (2018). Química Elevator: Um Jogo Digital para o Ensino da Tabela Periódica. In Simpósio Brasileiro de Jogos (pp. $1-4)$.

Feltre, R. (2005). Fundamentos da Química (4th ed.). São Paulo, SP: Editora Moderna.

Herpich, F., Jardim, R., Silva, R. F. da, Nunes, F., Voss, G., \& Medina, R. (2013). Jogos Sérios na Educação: Uma Abordagem para Ensino-Aprendizagem de Redes de Computadores (Fase I). In Nuevas Ideas en Informática Educativa TISE 2013 (pp. 617-620). Porto Alegre, RS.

Medeiros, I. G. de, Rego, J. de A. R. do, Costa, R. A. da, \& Júnior, J. M. dos S. L. (2020). Jogo Didático Como Ferramenta Pedagógica no Ensino de Tabela Periódica. In Estudos teórico-metodológicos nas ciências exatas, tecnológicas e da terra. Ponta Grossa, PR: Atena.

Parente, F. A. G., Santos, A. C. F. dos, \& Tort, A. C. (2013). Os 100 anos do átomo de Bohr. Revista Brasileira de Ensino de Física, 35(5).

Pedrisa, C. M. (2008). Características históricas do ensino de ciências. Ciências Em Foco, 1(1).

Peduzzi, L. O. Q., \& Basso, A. C. (2005). Para o ensino do átomo de Bohr no nível médio. Revista Brasileira de Ensino de Física, 27(4), 545-557.

Peruzzo, F. M., \& Canto, E. L. do. (2015). Química na abordagem do cotidiano. São Paulo, SP: Saraiva Didático.

Romanelli, L. I. (1996). O papel mediador do professor no processo de ensinoaprendizagem do conceito átomo. Química Nova Na Escola, 3, 27-31.

Sarmento, A. M. F., \& Oliveira, E. N. A. de. (2018). Como Elaborar um Jogo Didático para o Ensino-Aprendizagem dos Hidrocarbonetos. In Coleção Produtos Educativos e Metodologias de Ensino - Volume 2 (p. 143). Natal, RN: Offset Editora.

Silva, G. S. (2013). A abordagem do modelo atômico de Bohr através de atividades experimentais e de modelagem. Tese de doutoramento em Dissertação (Mestrado), Universidade Federal de Santa Maria, Santa Maria, RS.

Tarouco, L. M. R., Roland, L. C., Fabre, M.-C. J. M., \& Konrath, M. L. P. (2004). Jogos educacionais. In III Ciclo de Palestras sobre Novas Tecnologias na Educação. Porto Alegre, RS.

Tastle, W. J., Russell, J., \& Wiermann, M. J. (2008). A new measure to analyze student performance using the Likert scale. Information Systems Education Journal, 6(35), $1-7$.

Wangenheim, C. G. von, Petri, G., \& Borgatto, A. F. (2018). MEEGA+ KIDS : A Model for the Evaluation of Educational Games for Computing Education in Secondary School. Florianópolis: INE, UFSC. 